\title{
Tilapia male urinary pheromone stimulates female reproductive axis
}

\author{
Mar Huertas, Olinda G. Almeida, Adelino V.M. Canário, Peter C. Hubbard* \\ Centro de Ciências do Mar, CCMAR-CIMAR Laboratório Associado, Universidade do Algarve, Campus de Gambelas, 8005-139 Faro, Portugal
}

\section{A R T I C L E I N F O}

\section{Article history:}

Received 28 August 2013

Revised 17 November 2013

Accepted 26 November 2013

Available online 7 December 2013

\section{Keywords:}

Pheromone

Reproduction

Steroid release

Chemical communication

Sex steroid binding globulin

17,20ß-Dihydroxypregn-4-en-3-one

Cichlid

\begin{abstract}
A B S T R A C T
Mozambique tilapia males congregate in leks where they establish dominance hierarchies and attract females to spawn in sandy pits. Dominant males store more urine than subordinates and the pattern of urination and the high sensitivity of females to male urine suggest chemical signalling via the urine. Here we show that pre-ovulated and post-spawn females when exposed to dominant male urine increased significantly, in less than $1 \mathrm{~h}$, the release rate of the maturation-inducing steroid 17,20ßdihydroxypregn-4-en-3-one which is maintained elevated for at least $6 \mathrm{~h}$. This indicates a pheromonal role for male urine in the synchronisation of spawning. Furthermore, we show that the lack of affinity of $17,20 \beta$ P to sex steroid binding globulin explains, at least partly, its rapid release and lack of detection in the blood. Thus tilapia urine involvement in several communication processes confirms that cichlids have evolved a sophisticated chemical signalling system together with their complex visual, acoustic and behavioural displays.
\end{abstract}

(c) 2013 Elsevier Inc. All rights reserved.

\section{Introduction}

The use of waterborne chemical signals to control physiological process and behaviour has been observed in several fish (ChungDavidson et al., 2011; Hara, 1994; Rosenthal and Lobel, 2005; Stacey and Sorensen, 2005). Among this group of chemicals, sex pheromones are involved in reproduction by mediating location of suitable partners, evoking appropriate behavioural and endocrine responses, and improving synchronisation of gametogenesis, spawning, fertility and paternity (see reviews by Burnard et al., 2008; Stacey et al., 2003). The identification and characterisation of these compounds is important for understanding fish reproductive physiology (Stacey, 2011) and as a potential tool for population management (e.g., aquaculture and species invasions) (Johnson and Li, 2010; Sorensen and Stacey, 2004).

Pheromonal responses can occur at different levels, scales and contexts. Behavioural responses to a given stimulus occur usually within seconds, (Liley et al., 1986; Rouger and Liley, 1993; Stacey et al., 1989) but relatively rapid physiological changes, e.g. sex steroid synthesis and metabolism, are also possible within minutes or hours (Bayunova et al., 2011; Dulka et al., 1987; Scott et al., 1994).

Sex steroids are produced by the gonads through gonadotrophic stimulation and released into the blood to be transported to target organs. Therefore, steroid production is traditionally determined by analysis of blood samples in vertebrates. However, handling

\footnotetext{
* Corresponding author. Fax: +351 289800069.

E-mail address: phubbard@ualg.pt (P.C. Hubbard).
}

and sampling induce acute stress responses that may mask any response (Scott and Ellis, 2007; Scott et al., 2008). Consequently, there is increasing interest in the use of non-invasive procedures, including determination of steroid content in water and faeces, in fishes (Scott et al., 2008). The fish gill is considered to be the main route for release of free steroids at a rate that reflects largely their plasma concentrations. Indeed, several studies suggest that free steroids are preferentially released via the gills and are found at much lower concentrations in the urine or faeces compared to conjugated metabolites (Ellis et al., 2005; Miguel-Queralt and Hammond, 2008; Scott et al., 2008; Siefkes et al., 2003; Vermeirssen and Scott, 1996). Therefore, changes of steroid concentration in water samples can parallel those in blood, taking into account the dilution effect, and estimation of sex steroids in the water is a reliable indicator of fish endocrine status (Scott and Sorensen, 1994; Scott et al., 2008; Sebire et al., 2009). In cases of lack of correlation between blood plasma concentrations and release rates of steroids this has been ascribed to several factors including steroid characteristics and metabolism, and the presence of steroid binding globulins in blood with differing affinity for steroids (Scott and Sorensen, 1994; Scott et al., 2008).

The Mozambique tilapia (Oreochromis mossambicus; hereafter 'tilapia') is a polygynous maternal mouth-brooding African cichlid. In nature, males aggregate in breeding arenas (leks) and dominant males defend small territories centred on pits (nests) that they dig in the sand, adopting a typical black colouration; visiting females spawn in the territory of a dominant male and then move away from the males to mouth brood the eggs (Almeida et al., 2005; Barata et al., 2007; Oliveira and Almada, 1998; Russell et al., 
2012; Turner, 1986). Furthermore, signalling of male dominance via controlled urination has been demonstrated. Unlike subordinate males and females, dominant tilapia males store urine which is a vehicle for potent odorants actively released during aggressive disputes and mating behaviour (Almeida et al., 2005; Barata et al., 2007, 2008; Miranda et al., 2005). Moreover, the urinary bladders of dominant males are larger and more muscular than those of subordinate males or females, suggesting an adaptation facilitating storage of larger urine volumes for longer and more frequent urination in the appropriate social context, which may modulate aggression between opponent males (Keller-Costa et al., 2012). Males can discriminate the sexual status of females using olfactory cues (Miranda et al., 2005) and when in the presence of ovulated females, their urination rate increases (Almeida et al., 2005; Barata et al., 2008). The olfactory potency of male urine depends on the social status of the donor (Barata et al., 2007). These observations indicate that tilapia males release a pheromone via the urine which influences female spawning (Barata et al., 2008). However, the physiological and/or behavioural effect of the male pheromone on females is still unknown.

To determine the possible priming effect of the sex pheromonal compound present in male urine on female tilapia we measured their response, in terms of sex steroids, to male urine. We chose to measure steroids secreted mainly during the secondary growth phase (testosterone and $17 \beta$-estradiol; $\mathrm{E}_{2}$ ) and during final maturation of the oocytes $(17,20 \beta-\mathrm{P})$. Testosterone is produced by the theca cells surrounding the follicle under gonadotrophic stimulation and has positive feedback effects in the pituitary (Nagahama et al., 1995). Testosterone is the precursor of $E_{2}$ produced in the granulosa cells, which promotes ovarian growth through the stimulation of synthesis and secretion of vitellogenin and egg shell proteins in the liver (Lubzens et al., 2010; Nagahama et al., 1995; Senthilkumaran et al., 2004; Young et al., 2005). After oocyte growth, a shift in steroidogenesis leads to the production of $17,20 \beta$-dihydroxypregn-4-en-3-one $(17,20 \beta-P)$ also in the granulosa cells which induces the resumption of meiosis and final oocyte maturation (Nagahama, 1997; Senthilkumaran et al., 2004). In goldfish $17,20 \beta-P$ is also released to the water and is perceived by males thereby stimulating the endocrine system, spermiation as well as increased fertility and paternity (Dulka et al., 1987; Scott and Sorensen, 1994; Zheng et al., 1997).

Here we establish that urine from tilapia males contains a pheromone that primes the female's reproductive system by increasing the production and release rates of the maturation-inducing steroid $17,20 \beta-P$. We also show that these changes can only be detected in the water, possibly because the tilapia plasma sex steroid binding globulin has low affinity for 17,20 3 -P.

\section{Materials and methods}

\subsection{Experimental animals}

Adult Mozambique tilapia (O. mossambicus) of both sexes were taken from a stock population established at the Centre of Marine Sciences, University of the Algarve. Fish were tagged and 8 groups of one male and four females were setup in tanks of $250 \mathrm{~L}$ with sand substratum and kept at $27 \pm 1{ }^{\circ} \mathrm{C}$ under a photoperiod of $12 \mathrm{~h}$ light/12 h dark (lights on at 7.30 a.m.) and fed twice daily. Spawning occurred spontaneously in each tank, producing viable offspring. After each spawning, as soon as the females were seen carrying the eggs (usually within less than a day), they were taken from their mouth to maintain the females' ovulatory cycle and predict the next ovulation (Miranda et al., 2005). Twice a week, urine samples were taken from each of the 8 males, pooled with equal volumes of urine from each male and frozen $\left(-20^{\circ} \mathrm{C}\right)$ as previously described (Keller-Costa et al., 2012). Fish care and experimentation complied with the guidelines of the European Union Council (86/609/EU) and Portuguese legislation for the use of laboratory animals under a "Group-1" license issued by the veterinary directorate "Direcção Geral de Veterinária" of the Ministry of Agriculture, Rural Development and Fisheries of Portugal.

\subsection{Exposure of females to male urine}

Pre-ovulatory and post-spawning females were exposed to male urine and were expected to have different endocrine response as they represent different gonadal states. Only females with a regular ovulation cycle were used. A female was determined as regular if 3 consecutive ovulation cycles were of the same length ( \pm 2 days). Females were pre-ovulatory two days prior to the predicted date of ovulation and post-spawn three days after the last ovulation. Ovulation cycle length at $25^{\circ} \mathrm{C}$ of regular females is around 15 days (between 9 and 19 days) (Miranda et al., 2005). Experimental females, average weight $64.84 \mathrm{~g} \pm 1.63$, were placed in a glass isolation tank overnight and on the next day (i.e., one day prior to ovulation, or four days after spawning, respectively), each female was placed in an identical tank with a volume of clean water (de-chlorinated tapwater) proportional to the weight of the fish $10 \mathrm{~g} \mathrm{~L}^{-1} ; 6-8.5 \mathrm{~L}$, (Scott et al., 2008). After $1 \mathrm{~h}, 1 \mathrm{~L}$ of water was taken (by siphoning with a tube previously placed in the tank) for extraction (see below) and replaced with clean water. A volume of the pooled male urine was added to the tank to give a dilution 1:10,000 of urine: water. One hour later, another litre of water was taken for extraction and replaced with another litre of clean water containing male urine (at $1: 10,000)$. This process was repeated 2,4 and $6 \mathrm{~h}$ after the initial addition of the male urine. At the end of the experiment urine and blood samples (from 6 to 8 females per group) were taken from each female under anaesthesia with MS222 (50 $\mathrm{mg} \mathrm{L}^{-1}$ water). Control experiments were carried out exactly as described above except that the urine was replaced with distilled water. Another series of controls was carried out in exactly the same manner except that no fish was present (using $5 \mathrm{~L}$ water and male urine at 1:10,000) and no steroids were detected. Each female was used four times; as pre- and as post-ovulated, both in the presence and absence of male urine. The order of treatment was varied among females, but all were killed after the final exposure and replaced in the family tanks by new females. At least one ovulation cycle was allowed between successive treatments, when females were returned to their original family tanks. Total steroids (free plus sulphate and glucuronide) in the pool of male urine was; $24.5 \mathrm{ng} \mathrm{ml}^{-1}$ for $17,20 \beta \mathrm{P}, 14.3 \mathrm{ng} \mathrm{ml}^{-1}$ for cortisol, $34.1 \mathrm{ng} \mathrm{ml}^{-1}$ for testosterone and undetectable for $\mathrm{E}_{2}$.

\subsection{Steroid analysis}

Blood plasma and urine $(100 \mu \mathrm{l})$ were mixed with $100 \mu \mathrm{l}$ of distilled water and extracted twice with $4 \mathrm{ml}$ of diethyl ether to obtain free steroids. Water samples were extracted using 'Isolute' C18 $500 \mathrm{mg}$ solid-phase extraction cartridges (International Sorbent Technology Ltd., Hengoed, UK), under vacuum (flow rate approximately $4 \mathrm{ml} \mathrm{min}^{-1}$ ), according to the manufacturer's instructions. Methanol $(10 \mathrm{ml})$ was used to activate the cartridges and to elute the steroids.

Extracts were dried under nitrogen, reconstituted in $0.5 \mathrm{M}$ phosphate-gelatine buffer, $\mathrm{pH} 7.6$ and steroids measured by radioimmunoassay (RIA): $E_{2}$ (Guerreiro et al., 2002) and 17,20ßP (Canario et al., 1989) and testosterone. The testosterone antiserum was kindly donated by Dr. A.P. Scott and had the following crossreactions: $63 \%$ for androstenedione, $35 \%$ for 11 -ketotestosterone, $55 \%$ for $11 \beta$-hydroxytestosterone, $40 \%$ for $5 \alpha$-androstan- $17 \beta$ ol-3-one, $31 \%$ for $5 \beta$-androstan- $17 \beta$-ol-3-one, $12 \%$ for $5 \beta$-androstane-3 $\alpha, 17 \beta$-diol, $25 \%$ for $5 \alpha$-androstane- $3 \alpha, 17 \beta$-diol. The 
intra-assay and inter-assay coefficients of variation were as follows: $\mathrm{E}_{2} 6.6 \%$ and $14.2 \%$, testosterone $5.0 \%$ and $8.2 \%, 17,20 \beta \mathrm{P}$ $4.6 \%$ and $9.2 \%$.

\subsection{Steroid binding in blood}

The methodology to determine steroid binding in the plasma followed Scott et al. (2005). Serial dilutions of female tilapia plasma $(1 / 2.5-1 / 160, v / v)$ in $50 \mathrm{mM}$ sodium phosphate buffer, $\mathrm{pH}$ 7.6 , containing $0.1 \%$ gelatine were incubated (in duplicate) with $0.5 \mathrm{nM}$ of tritiated steroids at $4{ }^{\circ} \mathrm{C}$ for $2 \mathrm{~h}$. The free and bound fractions were separated using dextran coated charcoal and the supernatant free fraction counted for radioactivity. The binding affinity $\left(K_{\mathrm{d}}\right)$ and maximum binding sites capacity $\left(B_{\max }\right)$ for $\mathrm{E}_{2}$ were determined by incubating plasma diluted $1: 10(\mathrm{v} / \mathrm{v})$ with increasing concentrations $(0.2-60 \mathrm{nM})$ of ${ }^{3}[\mathrm{H}] \mathrm{E}_{2}$ with or without $1.5 \mathrm{mM}$ 'cold' $\mathrm{E}_{2}$ for $2 \mathrm{~h}$ at $4{ }^{\circ} \mathrm{C}$. The dissociation constant $\left(K_{\mathrm{d}}\right)$ and binding capacity $\left(B_{\max }\right)$ were calculated by Scatchard plot with the Ligand Binding Module of Sigmaplot (Systat Software Inc., UK).

Binding specificity was determined by incubating plasma samples (diluted 1:15) with $0.2 \mathrm{nM}^{3}[\mathrm{H}] \mathrm{E}_{2}$ with or without cold competitors for $60 \mathrm{~min}$ at $4{ }^{\circ} \mathrm{C}$. The concentration of cold competitor that displaced $50 \%$ of radioligand bound $\left(\mathrm{EC}_{50}\right)$, the relative binding affinity (RBA) and the concentration of radioinert competitor which bound $50 \%$ of specific bound in absence of radioligand $\left(K_{\mathrm{i}}\right)$ were calculated using the ligand binding module of Sigmaplot scientific graphing software (Systat Software Inc., UK).

\subsection{Statistics}

Data were analysed by three-way analysis of variance with treatment, stage and fluid (blood or urine) as factors, or treatment, stage and time as factors (water). Statistically significant effects $(P<0.05)$ were tested by the Holm-Sidak method in Sigmaplot.

\section{Results}

\subsection{Effect of urinary pheromone on blood and urine steroid levels}

Exposure to male urine had no apparent effect both on plasma and urine steroid concentrations (Fig. 1). However, the possibility that rapid, temporary changes may have occurred within the duration of the experiment cannot be excluded. Pre-ovulated females had significantly higher levels of blood plasma testosterone $\left(17.1 \pm 2.39 \mathrm{ng} \mathrm{ml}^{-1}\right)$ than post-spawn females $\left(3.9 \pm 1.06 \mathrm{ng} \mathrm{ml}^{-1}\right)$, but not of any of the other steroids, irrespective of being exposed to urine or not (Fig. 1). The mean levels of plasma $E_{2}$ were $10.5 \pm 2.32 \mathrm{ng} \mathrm{ml}^{-1}$. Plasma $17,20 \beta \mathrm{P}$ was detected at concentrations below $0.1 \mathrm{ng} \mathrm{ml}^{-1}$.

\subsection{Effect of urinary pheromone on steroids released to the water}

Overall, release rates of $E_{2}$ and testosterone were significantly higher in pre-ovulated than post-spawn females, but there was no significant effect of urine exposure (Fig. 2).

However, exposure to male urine sharply increased within $1 \mathrm{~h}$ of treatment the release rate of $17,20 \beta P$ to the water by pre- and post-spawn female tilapia (Fig. 2). The release rate of $17,20 \beta \mathrm{P}$ in females exposed to male urine remained significantly higher than controls for both pre- and post-spawn females over the $6 \mathrm{~h}$ of analysis. In contrast, the release rate of $17,20 \beta P$ decreased compared to initial values in females which received only distilled water.

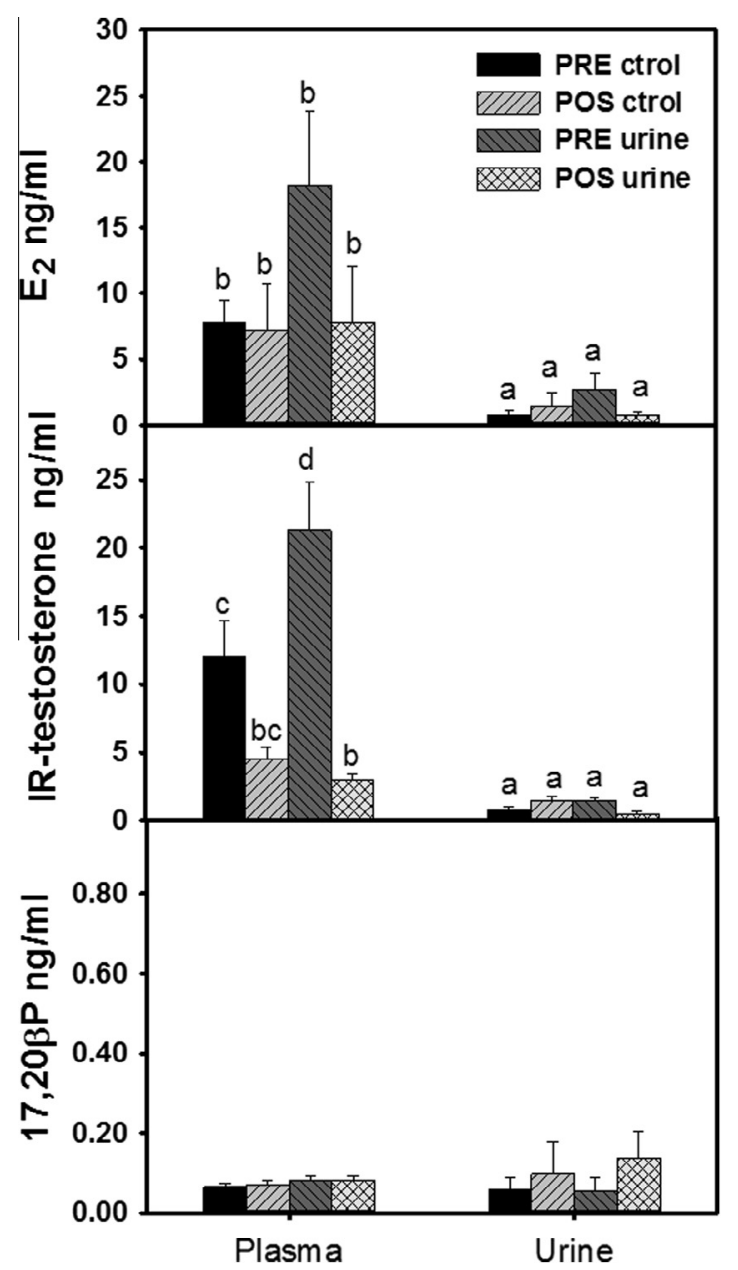

Fig. 1. Plasma and urine concentrations of steroids in pre-ovulated and post-spawn tilapia. Plasma ( $n=6-8)$ and urine $(n=4-6)$ concentrations (mean \pm standard error) of $E_{2}$, testosterone and $17,20 \beta \mathrm{P}$ after $6 \mathrm{~h}$ of exposure of female tilapia to distilled water (control) or male urine (diluted 1:10,000). PRE ctrol, pre-ovulated female controls; POS ctrol, post-spawn female controls; PRE urine, pre-ovulated females, urine-exposed; POS urine, post-spawn females, urine-exposed. Different letters indicate statistical significance $(P<0.05)$.

\subsection{Sex steroid binding in blood}

The blood of female tilapia binds preferably $E_{2}$ with high affinity $\left(K_{\mathrm{d}}=14 \mathrm{nM}\right)$ and moderate capacity (54 nM) (Supplementary Figure 1). The estimated affinity for testosterone $\left(K_{\mathrm{d}}=33 \mathrm{nM}\right)$ was slightly lower and the capacity slightly higher ( $99 \mathrm{nM})$ but of the same order of magnitude. Binding affinity for steroids and metabolites previously identified in fish, including 17,20ßP, was markedly lower than $\mathrm{E}_{2}$ or testosterone (Table 1).

\section{Discussion}

A pheromone present in urine from dominant tilapia males stimulates the release of $17,20 \beta \mathrm{P}$ in pre- and post-ovulated tilapia females. Considering the established role of $17,20 \beta \mathrm{P}$ as maturation-inducing steroid (Nagahama, 1997) and the suggested role in primary follicles (Zapater et al., 2012), the stimulation of $17,20 \beta$ P production and release demonstrates a specific priming effect for the male urine pheromone to accelerate reproduction. The involvement of urine in several communication processes confirms that cichlids have evolved a sophisticated chemical signalling system together with their complex visual (Maruska et al., 2011), 


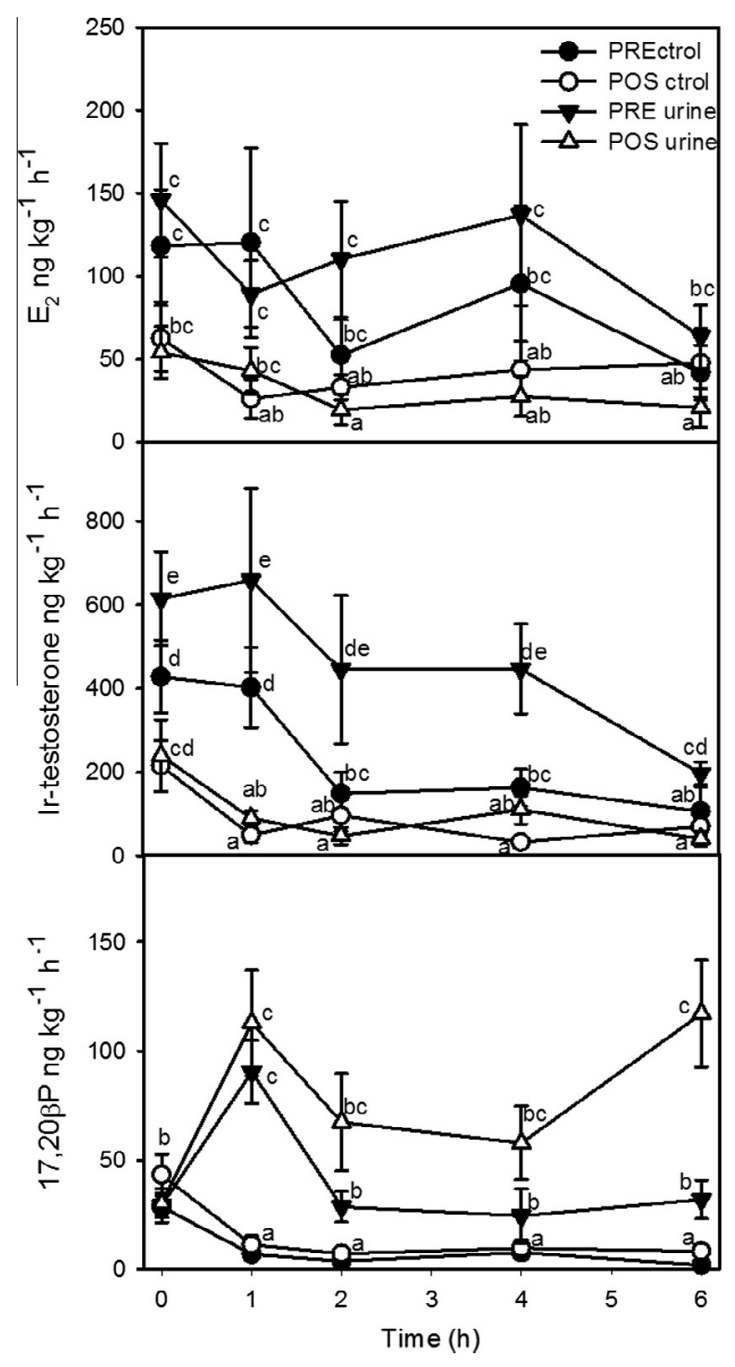

Fig. 2. Release rates of steroids by pre-ovulated and post-spawn tilapia females. Release rates (mean \pm standard error, $n=6-8$ ) of $E_{2}$, testosterone and $17,20 \beta \mathrm{P}$ after exposure to distilled water (control) or male urine (diluted 1:10,000). PRE ctrol, preovulated female controls; POS ctrol, post-spawn female controls; PRE urine, preovulated females, urine-exposed; POS urine, post-spawn females, urine-exposed. Different letters indicate statistical significance $(P<0.05)$.

Table 1

Specificity parameters of plasma sex steroid binding in female tilapia. Relative binding affinities (RBA) were determined by comparing the concentration of ligand to displace $50 \%$ of the specific binding $\left(\mathrm{EC}_{50}\right)$ to that for $17 \beta$-estradiol.

\begin{tabular}{|c|c|c|}
\hline Steroid & $\mathrm{EC}_{50}$ & RBA \\
\hline $17 \beta$-Estradiol & 6.4 & 100.0 \\
\hline Testosterone & 17.8 & 35.7 \\
\hline Androstenedione & 24.2 & 26.3 \\
\hline $11 \beta$-Hydroxytestosterone & 97.9 & 6.5 \\
\hline 11-Deoxycortisol & 101.2 & 6.3 \\
\hline 17-Hydroxyprogesterone & 107.4 & 5.9 \\
\hline Testosterone sulphate & 137.6 & 4.6 \\
\hline 11-Ketotestosterone & 150.3 & 4.2 \\
\hline $17,20 \beta$-Dihydroxypregn-4-en-3-one & 192.4 & 3.3 \\
\hline Progesterone & 276.4 & 2.3 \\
\hline 20ß-Hydroxypregn-4-en-3-one & 284.2 & 2.2 \\
\hline $17,20 \beta, 21$ P-Dihydroxypregn-4-en-3-one & 302.6 & 2.1 \\
\hline Cortisol & 321.1 & 2.0 \\
\hline Testosterone glucuronide & 434.0 & 1.5 \\
\hline $17,20 \alpha$-Dihydroxypregn-4-en-3-one & $2.6 \mathrm{E}+03$ & 0.2 \\
\hline $3 \alpha, 17,21$-Trihydroxy-5 $\beta$-pregnan-20-one & $8.3 \mathrm{E}+11$ & 0.0 \\
\hline $17 \beta$-Estradiol 3-sulphate & $1.5 \mathrm{E}+04$ & 0.0 \\
\hline $17 \beta$-Estradiol 17-glucuronide & $>10 \mathrm{E}+11$ & 0.0 \\
\hline
\end{tabular}

acoustic (Amorim et al., 2003; Danley et al., 2012) and behavioural displays (Oliveira, 2005).

Fish urine has been found to be a vehicle for pheromones also in other species. Urine from mature female rainbow trout (Oncorhynchus mykiss) stimulates $\mathrm{LH}$ release and steroidogenesis in males (Scott et al., 1994) and contains an attractant for mature males (Yambe et al., 2006). Urine and ovarian fluid from female Atlantic salmon (Salmo salar) increased plasma concentrations of sex steroid hormones in mature conspecific male parr (Olsen et al., 2001). Female masou salmon (Oncorhynchus masou) urine contains an amino acid which advertises spawning readiness attracting mature males (Yambe and Yamazaki, 2001). Urine from female goldfish contains $17,20 \beta \mathrm{P}$ sulphate and prostaglandin $\mathrm{F} 2 \alpha$ released as by females as part of a complex bouquet of ovulatory pheromone, which includes $17,20 \beta \mathrm{P}$ and androstenedione released primarily through the gills (Appelt and Sorensen, 1999, 2007; Poling et al., 2001; Sorensen et al., 1995, 2000; Van der Kraak et al., 1989). Post-vitellogenic female goldfish develop an LH surge triggered by environmental and social factors, and release androstenedione which increases male aggressiveness. As the LH surge progresses $17,20 \beta \mathrm{P}$ is released causing an LH surge in males and spermiation (Kobayashi et al., 1986), as well as increased swimming and inspection behaviour (Defraipont and Sorensen, 1993; Poling et al., 2001). At a later stage in the LH surge 17,20ßP sulphate is released through the urine inducing intense bouts of chasing and following and small increases in LH in males (Poling et al., 2001; Sorensen et al., 1995).

In tilapia, males release urine in a controlled manner to signal dominance to other males (Almeida et al., 2005; Barata et al., 2007) and to females (Barata et al., 2008). Urine from dominant males has stronger olfactory potency than that of subordinate males, and dominant males are also able to store more urine (Barata et al., 2008), possibly as a result of a more muscular urinary bladder (Keller-Costa et al., 2012). The nature of the tilapia pheromone component(s) released to the water via the urine is not known, although a conjugated sterol has been suggested (Barata et al., 2008).

The best known physiological function of $17,20 \beta \mathrm{P}$ is as oocyte final maturation inducer, triggering the resumption of meiosis and germinal vehicle breakdown in oocytes just prior to ovulation (Nagahama, 1987; Pankhurst, 2008; Scott and Canario, 1987). Thus, the increased production of $17,20 \beta \mathrm{P}$ in pre-ovulatory tilapia after exposure to male urine strongly suggests a synchronisation of spawning through the induction of final oocyte maturation. This is consistent with the observation that the urine of pre-ovulated females has a stronger odour potency than post-spawn females (Miranda et al., 2005). A recent investigation also suggested a role for $17,20 \beta \mathrm{P}$ in the development of primary ovarian follicles under the stimulation of follicle stimulating hormone ( $\mathrm{FSH}$; Zapater et al., 2012). Since the tilapia ovary is asynchronous, with a batch of oocytes undergoing a full cycle approximately every 2 weeks (Miranda et al., 2005), the increased release of 17,20ßP and metabolites by post-spawn females could be linked to the stimulation of a new batch of oocytes. Thus, the premise that links increased $17,20 \beta \mathrm{P}$ production after urine exposure with spawning is consistent with the observation of synchronisation of the reproductive event in goldfish and other fish species after interaction of malefemale conspecifics (Colombo et al., 1980; Degani and Schreibman, 1993; Liley et al., 1986; Vanweerd et al., 1991).

Since tilapia have no olfactory sensitivity to $17,20 \beta \mathrm{P}$ (Frade et al., 2002), it is unlikely that the release of $17,20 \beta \mathrm{P}$ has a signalling function in males, e.g., to signal spawning readiness. However, as with the tilapia testis (Kime and Heyder, 1983), the ovary is able to metabolize a variety of sex steroids including $17,20 \beta \mathrm{P}$ (Rocha and Reis-Henriques, 1996, 1998), which could themselves act as female pheromone. 
The observed increase in $17,20 \beta \mathrm{P}$ release was rapid with higher rates of release within $1 \mathrm{~h}$ of adding male urine and declining thereafter. In goldfish the response is also rapid with luteinizing hormone (LH) levels and milt volumes increasing at approximately the time when increased $17,20 \beta-P$ release by ovulatory females commenced (Stacey et al., 1989). The rapid response is consistent with the mating strategy of the tilapia: male occupy territories temporarily and females and males tend to synchronise reproduction within a limited time frame (Oliveira and Almada, 1998). Thus, females are exposed to urine from males for a brief time when they are actively seeking a mate and come into their vicinity (Miranda et al., 2005).

A striking result from the present work was that the hormonal response to male urine was observed in the water but not in the plasma or urine from females. This was largely due to the fact that plasma and urinary levels of $17,20 \beta$ P were low and that samples were taken only after $6 \mathrm{~h}$ whereas the maximum release of the steroid occurred in less than $1 \mathrm{~h}$. However, the question arises as to why levels of $E_{2}$ (and testosterone) and $1720 \beta P$ in plasma differ by almost 2 orders of magnitude while their release rates are fairly similar? Similar observations of dissociation between plasma and released steroid have been made in goldfish (Scott and Sorensen, 1994) and, as recently discussed, several factors may contribute to the strength of relationships between free steroids in plasma and released (Scott et al., 2008). As shown here, the tilapia sex steroid binding globulin, similar to other teleost fishes (Chang et al., 1994; Miguel-Queralt et al., 2005), has high affinity to $E_{2}$ and testosterone while it has low affinity for $1720 \beta \mathrm{P}$. Thus, our results concur with the hypothesis first put forward by Scott and Sorensen (1994) that retention of free steroids in blood plasma depends on their capacity to bind to sex steroid binding globulin. Uptake of steroids from the water is also related to the affinity to sex steroid binding globulin (Miguel-Queralt and Hammond, 2008; Scott et al., 2005). As a result, $17,20 \beta \mathrm{P}$, produced by the follicles in significant amounts and lacking affinity to the plasma carrier is rapidly released, most likely through the gills (Scott et al., 2008; Vermeirssen and Scott, 1996).

\section{Conclusions}

In conclusion, urine from male tilapia contains a pheromone that dramatically affects $17,20 \beta \mathrm{P}$ metabolism in females, less than $1 \mathrm{~h}$ after exposure; the first time a primer effect of male pheromone on females has been reported in a cichlid. Furthermore, this pheromonal effect was manifest using non-invasive measurement of steroids in the water, but may not have been so obvious using conventional blood sampling. This method may prove to be a simple and rapid bioassay for the study of pheromone function(s) in fish and challenges the traditional measuring of steroids in plasma to understand physiological processes.

\section{Acknowledgments}

Funded by European Union-FSE/FEDER and Ministério da Ciência e do Ensino Superior, Portugal through Fundação para a Ciência e Tecnologia, Portugal (Grant numbers POCI/BIA-BDE/55463/2004 and SFRH/BPD/26339/2006). The authors are grateful to Elsa Couto for her help with the steroid radio-immunoassays.

\section{Appendix A. Supplementary data}

Supplementary data associated with this article can be found, in the online version, at http://dx.doi.org/10.1016/j.ygcen.2013. 11.024 .

\section{References}

Almeida, O.G., Miranda, A., Frade, P., Hubbard, P.C., Barata, E.N., Canario, A.V.M. 2005. Urine as a social signal in the Mozambique tilapia (Oreochromis mossambicus). Chem. Senses 30, I309-I310.

Amorim, M.C.P., Fonseca, P.J., Almada, V.C., 2003. Sound production during courtship and spawning of Oreochromis mossambicus: male-female and malemale interactions. J. Fish Biol. 62, 658-672.

Appelt, C., Sorensen, P., 1999. Freshwater fish release urinary pheromones in a pulsatile manner. In: Johnston, R., Müller-Schwarze, D., Sorensen, P. (Eds.), Advances in Chemical Signals in Vertebrates. Springer, US, pp. 247-256.

Appelt, C.W., Sorensen, P.W., 2007. Female goldfish signal spawning readiness by altering when and where they release a urinary pheromone. Anim. Behav. 74, $1329-1338$.

Barata, E.N., Fine, J.M., Hubbard, P.C., Almeida, O.G., Frade, P., Sorensen, P.W. Canario, A.V.M., 2008. A sterol-like odorant in the urine of Mozambique tilapia males likely signals social dominance to females. J. Chem. Ecol. 34, 438-449.

Barata, E.N., Hubbard, P.C., Almeida, O.G., Miranda, A., Canario, A.V., 2007. Male urine signals social rank in the Mozambique tilapia (Oreochromis mossambicus). BMC Biol. 5, 54.

Bayunova, L., Semenkova, T., Canario, A.V.M., Gerasimov, A., Barannikova, I., 2011. Free and conjugated androgen and progestin levels in the serum of stellate sturgeon (Acipenser stellatus, Pallas) males treated with female coelomic fluid. J. Appl. Ichthyol. 27, 655-659.

Burnard, D., Gozlan, R.E., Griffiths, S.W., 2008. The role of pheromones in freshwater fishes. J. Fish Biol. 73, 1-16.

Canario, A.V., Scott, A.P., Flint, A.P., 1989. Radioimmunoassay investigations of 20bhydroxylated steroids in maturing/ovulating female rainbow trout (Salmo gairdneri). Gen. Comp. Endocrinol. 74, 77-84.

Chang, C.-F., Lee, Y.-H., Yoshida, T., Sun, L.-T., 1994. Characterization of the plasma sex steroid-binding protein in eel (Anguilla japonica). Comp. Biochem. Physiol. B. Biochem. Mol. Biol. 108, 189-197.

Chung-Davidson, Y.-W., Huertas, M., Li, W., 2011. A review of research in fish pheromones. In: Thiel, M., Breithaupt, T. (Eds.), Chemical Communication in Crustaceans. Springer, New York, pp. 467-482.

Colombo, L., Marconato, A., Belvedere, P., Friso, S., 1980. Endocrinology of teleost reproduction: a testicular steroid pheromone in the black goby, Gobious jozo L. Ital. J. Zool. 47, 355-364.

Danley, P.D., Husemann, M., Chetta, J., 2012. Acoustic diversity in Lake Malawi's rock-dwelling cichlids. Environ. Biol. Fishes 93, 23-30.

Defraipont, M., Sorensen, P.W., 1993. Exposure to the pheromone $17 \alpha, 20 \beta-$ dihydroxy-4-pregnen-3-one enhances the behavioral spawning success, sperm production and sperm motility of male goldfish. Anim. Behav. 46, 245256.

Degani, G., Schreibman, M.P., 1993. Pheromone of male blue gourami and its effect on vitellogcnesis, steroidogenesis and gonadotropin cells in pituitary of the female. J. Fish Biol. 43, 475-485.

Dulka, J.G., Stacey, N.E., Sorensen, P.W., Vanderkraak, G.J., 1987. A steroid sexpheromone synchronizes male-female spawning readiness in goldfish. Nature $325,251-253$.

Ellis, T., James, J.D., Scott, A.P., 2005. Branchial release of free cortisol and melatonin by rainbow trout. J. Fish Biol. 67, 535-540.

Frade, P., Hubbard, P.C., Barata, E.N., Canario, A.V.M., 2002. Olfactory sensitivity of the Mozambique tilapia to conspecific odours. J. Fish Biol. 61, 1239-1254.

Guerreiro, P.M., Fuentes, J., Canario, A.V., Power, D.M., 2002. Calcium balance in sea bream (Sparus aurata): the effect of oestradiol-17ß. J. Endocrinol. 173, 377-385.

Hara, T.J., 1994. Olfaction and gustation in fish - an overview. Acta Physiol. Scand. $152,207-217$.

Johnson, N.S., Li, W.M., 2010. Understanding behavioral responses of fish to pheromones in natural freshwater environments. J. Comp. Physiol. A. Sens. Neural Behav. Physiol. 196, 701-711.

Keller-Costa, T., Lopes, O.S., Lima, M., Hubbard, P.C., Iacovella, A., Canário, A.V.M. Almeida, O., Barata, E.N., 2012. Muscular hypertrophy of urinary bladders in dominant tilapia facilitates the control of aggression through urinary signals. Behaviour 149, 953-975.

Kime, D.E., Heyder, M., 1983. The effect of temperature and gonadotropin on testicular steroidogenesis in Sarotherodon (Tilapia) mossambicus in vitro. Gen. Comp. Endocrinol. 50, 105-115.

Kobayashi, M., Aida, K., Hanyu, I., 1986. Pheromone from ovulatory female goldfish induces gonadotropin surge in males. Gen. Comp. Endocrinol. 63, 451-455.

Liley, N.R., Fostier, A., Breton, B., Tan, E.S.P., 1986. Endocrine changes associated with spawning behavior and social-stimuli in a wild population of rainbow trout (Salmo gairdneri). 2. Females. Gen. Comp. Endocrinol. 62, 157-167.

Lubzens, E., Young, G., Bobe, J., Cerda, J., 2010. Oogenesis in teleosts: how fish eggs are formed. Gen. Comp. Endocrinol. 165, 367-389.

Maruska, K.P., Levavi-Sivan, B., Biran, J., Fernald, R.D., 2011. Plasticity of the reproductive axis caused by social status change in an African cichlid fish: I. Pituitary gonadotropins. Endocrinology 152, 281-290.

Miguel-Queralt, S., Avvakumov, G.V., Blazquez, M., Piferrer, F., Hammond, G.L., 2005 Sea bass (Dicentrarchus labrax) sex hormone binding globulin: molecular and biochemical properties and phylogenetic comparison of its orthologues in multiple fish species. Mol. Cell. Endocrinol. 229, 21-29.

Miguel-Queralt, S., Hammond, G.L., 2008. Sex hormone-binding globulin in fish gills is a portal for sex steroids breached by xenobiotics. Endocrinology 149, 4269 4275 . 
Miranda, A., Almeida, O.G., Hubbard, P.C., Barata, E.N., Canario, A.V., 2005. Olfactory discrimination of female reproductive status by male tilapia (Oreochromis mossambicus). J. Exp. Biol. 208, 2037-2043.

Nagahama, Y., 1987. 17 $\alpha, 20 \beta$-Dihydroxy-4-pregnen-3-one - a teleost maturationinducing hormone. Dev. Growth Differ. 29, 1-12.

Nagahama, Y., 1997. 17 $2,20 \beta$-Dihydroxy-4-pregnen-3-one, a maturation-inducing hormone in fish oocytes: mechanisms of synthesis and action. Steroids 62, 190 196.

Nagahama, Y., Yoshikuni, M., Yamashita, M., Tokumoto, T., Kasu, Y., 1995. Regulation of oocyte growth and maturation in fish. Curr. Top. Dev. Biol. 30, $103-145$.

Oliveira, R.F., 2005. Neuroendocrine mechanisms of alternative reproductive tactics. In: Sloman, K.A., Wilson, R.W., Balshine, S. (Eds.), Behaviour and Physiology of Fish. Academic Press, Amsterdam, pp. 297-357.

Oliveira, R.F., Almada, V.C., 1998. Mating tactics and male-male courtship in the lek-breeding cichlid Oreochromis mossambicus. J. Fish Biol. 52, 1115-1129.

Olsen, K.H., Bjerselius, R., Mayer, I., Kindahl, H., 2001. Both ovarian fluid and female urine increase sex steroid hormone levels in mature Atlantic salmon (Salmo salar) male parr. J. Chem. Ecol. 27, 2337-2349.

Pankhurst, N.W., 2008. Gonadal steroids: functions and patterns of change. In: Rocha, M.J., Arukwe, A., Kapoor, B.G. (Eds.), Fish Reproduction. Science Publishers, New Hampshire, pp. 67-111.

Poling, K.R., Fraser, E.J., Sorensen, P.W., 2001. The three steroidal components of the goldfish preovulatory pheromone signal evoke different behaviors in males. Comp. Biochem. Physiol. B. Biochem. Mol. Biol. 129, 645-651.

Rocha, M.J., Reis-Henriques, M.A., 1996. Plasma and urine levels of C-18, C-19 and C 21 steroids in an asynchronous fish, the tilapia Oreochromis mossambicus (Teleostei, cichlidae). Comp. Biochem. Physiol. C. Comp. Pharmacol. Toxicol. 115, 257-264.

Rocha, M.J., Reis-Henriques, M.A., 1998. Steroid metabolism by ovarian follicles of the tilapia Oreochromis mossambicus (Teleostei, Cichlidae). Comp. Biochem. Physiol. B. Biochem. Mol. Biol. 121, 85-90.

Rosenthal, G.G., Lobel, P.S., 2005. Communication. In: Sloman, K.A., Wilson, R.W., Balshine, S. (Eds.), Behaviour and Physiology of Fish. Academic Press, Amsterdam, pp. 39-78.

Rouger, Y., Liley, N.R., 1993. Effect of social-environment on plasma hormones and availability of milt in spawning male rainbow trout (Oncorhynchus mykiss, Walbaum). Can. J. Zool. 71, 280-285.

Russell, D.J., Thuesen, P.A., Thomson, F.E., 2012. Reproductive strategies of two invasive tilapia species Oreochromis mossambicus and Tilapia mariae in Northern Australia. J. Fish Biol. 80, 2176-2197.

Scott, A.P., Canario, A.V.M., 1987. Status of oocyte maturation-inducing steroids in teleosts. In: Idler, D.R., Crim, L.W., Walsh, J.M. (Eds.), Proceedings of the Third International Symposium on Reproductive Physiology of Fish. Marine Science Research Laboratory, St John's, pp. 224-234.

Scott, A.P., Ellis, T., 2007. Measurement of fish steroids in water - a review. Gen. Comp. Endocrinol. 153, 392-400.

Scott, A.P., Hirschenhauser, K., Bender, N., Oliveira, R., Earley, R.L., Sebire, M., Ellis, T. Pavlidis, M., Hubbard, P.C., Huertas, M., Canario, A., 2008. Non-invasive measurement of steroids in fish-holding water: important considerations when applying the procedure to behaviour studies. Behaviour 145, 1307-1328.

Scott, A.P., Liley, N.R., Vermeirssen, E.L.M., 1994. Urine of reproductively mature female rainbow trout, Oncorhynchus mykiss (Walbaum), contains a priming pheromone which enhances plasma levels of sex steroids and Gonadotropin-Il in males. J. Fish Biol. 44, 131-147.

Scott, A.P., Pinillos, M.L., Huertas, M., 2005. The rate of uptake of sex steroids from water by Tinca tinca is influenced by their affinity for sex steroid binding protein in plasma. J. Fish Biol. 67, 182-200.

Scott, A.P., Sorensen, P.W., 1994. Time course of release of pheromonally active gonadal steroids and their conjugates by ovulatory goldfish. Gen. Comp. Endocrinol. 96, 309-323.

Sebire, M., Katsiadaki, I., Scott, A.P., 2009. Further refinement of the non-invasive procedure for measuring steroid production in the male three-spined stickleback Gasterosteus aculeatus. J. Fish Biol. 75, 2082-2094.
Senthilkumaran, B., Yoshikuni, M., Nagahama, Y., 2004. A shift in steroidogenesis occurring in ovarian follicles prior to oocyte maturation. Mol. Cell. Endocrinol. 215, 11-18.

Siefkes, M.J., Scott, A.P., Zielinski, B., Yun, S.S., Li, W.M., 2003. Male sea lampreys, Petromyzon marinus L., excrete a sex pheromone from gill epithelia. Biol. Reprod. 69, 125-132.

Sorensen, P.W., Scott, A.P., Kihslinger, R.L., 2000. How common hormonal metabolites function as relatively specific pheromonal signals in the goldfish. In: Norberg, B., Kjesbu, O.S., Andersson, E., Stefansson, S.O. (Eds.), Proceedings of the Sixth International Symposium on the Reproductive Physiology of Fish, 2000. Institute of Marine Research and University of Bergen, Bergen, pp. 125128.

Sorensen, P.W., Scott, A.P., Stacey, N.E., Bowdin, L., 1995. Sulphated 17,20ßdihydroxy-4-pregnen-3-one functions as a potent and specific olfactory stimulant with pheromonal actions in the goldfish. Gen. Comp. Endocrinol. $100,128-142$

Sorensen, P.W., Stacey, N.E., 2004. Brief review of fish pheromones and discussion of their possible uses in the control of non-indigenous teleost fishes. N.Z. J. Mar. Freshwat. Res. 38, 399-417.

Stacey, N., 2011. Chapter 9 - hormonally derived sex pheromones in fishes. In: Norris, D.O., Lopez, K.H. (Eds.), Hormones and Reproduction of Vertebrates. Academic Press, London, pp. 169-192.

Stacey, N., Sorensen, P., 2005. Reproductive pheromones. In: Sloman, K.A., Wilson, R.W., Balshine, S. (Eds.), Behaviour and Physiology of Fish. Academic Press, Amsterdam, pp. 359-412.

Stacey, N.E., Sorensen, P.W., Van Der Kraak, G.J., Dulka, J.G., 1989. Direct evidence that $17 \alpha, 20 \beta$-dihydroxy-4-pregnen-3-one functions as a goldfish primer pheromone: preovulatory release is closely associated with male endocrine responses. Gen. Comp. Endocrinol. 75, 62-70.

Stacey, N., Chojnacki, A., Narayanan, A., Cole, T., Murphy, C., 2003. Hormonally derived sex pheromones in fish: exogenous cues and signals from gonad to brain. Can. J. Physiol. Pharmacol. 81, 329-341.

Turner, G.F., 1986. Territory dynamics and cost of reproduction in a captive population of the colonial nesting mouthbrooder Oreochromis mossambicus (Peters). J. Fish Biol. 29, 573-587.

Van der Kraak, G., Sorensen, P.W., Stacey, N.E., Dulka, J.G., 1989. Periovulatory female goldfish release 3 potential pheromones - $17 \alpha, 20 \beta$ dihydroxyprogesterone, 17 $\alpha, 20 \beta$-dihydroxyprogesterone glucuronide, and $17 \alpha$-hydroxyprogesterone. Gen. Comp. Endocrinol. 73, 452-457.

Vanweerd, J.H., Sukkel, M., Bongers, A.B.J., Vanderdoes, H.M., Steynis, E., Richter, C.J.J., 1991. Stimulation of gonadal development by sexual interaction of pubertal African catfish, Clarias gariepinus. Physiol. Behav. 49, 217-223.

Vermeirssen, E.L.M., Scott, A.P., 1996. Excretion of free and conjugated steroids in rainbow trout (Oncorhynchus mykiss): evidence for branchial excretion of the maturation-inducing steroid, 17,20ß-dihydroxy-4-pregnen-3-one. Gen. Comp. Endocrinol. 101, 180-194.

Yambe, H., Kitamura, S., Kamio, M. Yamada, M., Matsunaga, S., Fusetani, N., Yamazaki, F., 2006. L-kynurenine, an amino acid identified as a sex pheromone in the urine of ovulated female masu salmon. Proc. Natl. Acad. Sci. USA 103, $15370-15374$

Young, G., Lokman, P.M., Kusakabe, M., Nakamura, I., Goetz, F.W., 2005. Gonadal steroidogenesis in teleost fish. In: Sherwood, N., Melamed, P. (Eds.), Hormones and Their Receptors in Fish Reproduction. World Scientific Press, Singapore, pp. $155-223$.

Yambe, H., Yamazaki, F., 2001. A releaser pheromone that attracts methyltestosterone-treated immature fish in the urine of ovulated female rainbow trout. Fish. Sci. 67, 214-220.

Zapater, C., Chauvigné, F., Scott, A.P., Gómez, A., Katsiadaki, I., Cerdà, J., 2012. Piscine follicle-stimulating hormone triggers progestin production in gilthead seabream primary ovarian follicles. Biol. Reprod. 87 (111), 111-113.

Zheng, W.B., Strobeck, C., Stacey, N., 1997. The steroid pheromone 4-pregnen$17 \alpha, 20 \beta$-diol-3-one increases fertility and paternity in goldfish. J. Exp. Biol. 200, 2833-2840. 